\title{
Functional Mobility, Depressive Symptoms, Level of Independence, and Quality of Life of the Elderly Living at Home and in the Nursing Home
}

Mehmet Gürhan Karakaya, PhD, Sevil Çuvalci Bilgin, PhD, Gamze Ekici, PhD, Nezire Köse, PhD, and Ayşe Saadet Otman, PhD

Objectives: To compare functional mobility, depressive symptoms, level of independence, and quality of life of the elderly living at home and in the nursing home.

Design: A prospectively designed, comparative study.

Setting: A nursing home and a university hospital department.

Participants: In this study, 33 elderly living in a nursing home and 25 elderly living at home, who fulfilled the inclusion criteria and volunteered to participate, were included.

Measurements: Sociodemographic characteristics were recorded. Functional mobility (Timed Up \& Go Test), depressive symptoms (Geriatric Depression Scale), level of independence (Kahoku Aging Longitudinal Study Scale), and quality of life (Visual
Analogue Scale) scores were compared between the groups.

Results: Functional mobility and independence level of the nursing home residents were higher than the home-dwelling elderly $(95 \% \mathrm{Cl}$ : $-4.88,-0.29$ and $0.41,6.30$, respectively), but they had more depressive symptoms ( $95 \% \mathrm{Cl}: 0.30,5.45)$, and their level of QoL was lower $(95 \% \mathrm{Cl}$ : $-15.55,-2.93)$.

Conclusion: These findings are thought to be important and of benefit for health care professionals and caregivers as indicating the areas that need to be supported for the elderly living at home (functional mobility and independence) and in the nursing home (depressive symptoms and quality of life). (J Am Med Dir Assoc 2009; 10: 662-666)

Keywords: Geriatric assessment; nursing home residents; home-dwelling elderly
The percentage of geriatric people is increasing in the Turkish population, as well as all over the world. According to the results of the Turkish Demographic and Health Survey (TDHS) 2003, the proportion of Turkish people older than 65 is $6.9 \%$ of the total population. ${ }^{1,2}$ The growing number of elderly people places increasing demands on

Muğla University, Muğla School of Health Sciences, Department of Physiotherapy and Rehabilitation, Muğla, Turkey (M.G.K.); Hacettepe University، Faculty of Health Sciences, Department of Physical Therapy and Rehabilitation, Ankara, Turkey(S.C.B., N.K.); Ahi Evran University, School of Physical Therapy and Rehabilitation, Kırşehir, Turkey(G.E.); Bilkent University, Ankara, Turkey(A.S.O.).

The authors have no conflicts of interest relating to this article.

Address correspondence to Mehmet Gürhan Karakaya, PhD, Muğla University, Muğla School of Health Sciences, Department of Physiotherapy and Rehabilitation, 48000, Muğla, Turkey. E-mail: mgkarakaya@mu.edu.tr.)

Copyright (C2009 American Medical Directors Association

DOI:10.1016/j.jamda.2009.06.002 the public health system, and on medical and social services.

Aging is a period that causes structural and functional disorders in the individual. Besides the physiological changes and diseases, social and mental problems may also be encountered in elderly people. ${ }^{1}$

Functional mobility, depressive symptoms, and level of dependency are commonly investigated parameters in the comprehensive geriatric assessment because of their relation with morbidity and because they help to define the areas in need of attention in order to improve health, function, and quality of life (QoL). ${ }^{3-14}$

Mobility, defined as the ability to move independently around the environment, is an essential part of many basic (getting in and out of the bed, bathing, dressing, eating, personal hygiene, using the toilet, and so forth) and instrumental (using the telephone, traveling via car or public transportation, shopping, housecleaning, handling money, taking medications, and 
so forth) activities of daily life (ADLs and IADLs). In the elderly population, decline in mobility often precedes the onset of disability in ADLs. ${ }^{3}$ Mobility limitations, which have been shown to be the strongest predictor of self-perceived disability, significantly restrict participation and can lead to social isolation, anxiety, and depression in older adults. ${ }^{3,4}$

Lack of motivation, social issues and cultural expectations, environmental factors, coexisting disease states, fear of falling, and many other factors contribute to functional impairment in older adults. In addition, nursing care that creates dependency was shown to be a significant factor causing functional impairment, further de-conditioning, and disability in elderly people in long-term care settings. ${ }^{15}$ Therefore, restorative care, which is a philosophy of care that focuses on preventing functional decline and restoring and maintaining residents in these settings at their optimal functioning and physical status, have gained increasing importance. ${ }^{15-18}$

In related literature, functional mobility, cognitive dysfunction, and depression as risk factors for falls ${ }^{5,6,8,12}$ and determinants of balance confidence (a person's level of confidence in the ability to maintain balance while performing specific daily activities) ${ }^{9}$ are the commonly investigated parameters. Their effects on ADLs, ${ }^{13}$ quality of life, ${ }^{5}$ and dependency, ${ }^{14}$ as well as the role of restorative care and rehabilitation in optimizing these factors, are also included in the literature. ${ }^{16-20}$ However, there is insufficient knowledge concerning the effect of residential status on functional mobility, depressive symptoms, independence, and quality of life of the elderly. Therefore, this study was performed to compare these parameters in elderly people living in the home setting and in the nursing home. The results of the present study will provide information for health care professionals to consider areas that need support, while planning and carrying out institutional or home care for elderly people.

\section{METHODS}

\section{Design and Participants}

This is a prospectively designed comparative study that was carried out between 2003 and 2004. Among 50 elderly people living in a nursing home and 43 home-dwelling elderly who were the visitors of the patients being followed at Hacettepe University, Neurosurgery Department, individuals meeting the inclusion criteria ( $\mathrm{n}=33$ living in a nursing home, $\mathrm{n}=25$ living at home) were included in the study. Institutional permission was gained from the director of the nursing home, and written informed consent was obtained from each participant in compliance with the Declaration of Helsinki.

Inclusion criteria for the study were the following: demonstrating the ability to follow verbal requests for movement or tasks and being able to ambulate more than $12 \mathrm{~m}(\sim 39 \mathrm{ft})$ without using assistive devices other than a straight cane. Subjects with a history of falling, clinical depression, dizziness, vertigo, visual impairment, progressive neurological disorder, stroke, amputation, unstable medical condition, cancer, and fracture as a result of osteoporosis were excluded. Because cognitive decline, particularly when executive functions (a set of cognitive skills that are necessary to plan, monitor, and exe- cute a sequence of goal-directed complex actions) are compromised, may worsen motor performance decline in the elderly population, individuals with a score of 24 or lower on the Mini Mental State Examination (MMSE) were also not included. $^{21-23}$ An MMSE cut-off score of 24 was used in this study, as it was shown to have a quite high sensitivity and specificity in mild dementia diagnosis in Turkish elderly people. ${ }^{24}$

\section{Sociodemographic Characteristics}

Age (year), gender (male/female), and marital status (married, widow/er, divorced) of the subjects were recorded as the sociodemographic data. Subjects who were living at home were asked if they were living alone or with their family.

\section{Functional Mobility}

The Timed Up \& Go (TUG) test, which was shown to be reliable and valid, ${ }^{25}$ was used in this study to quantify functional mobility. For the TUG test, subjects were observed and timed while rising from an arm chair, walking $3 \mathrm{~m}$ $(\sim 10 \mathrm{ft})$, turning, walking back, and sitting down again. The subjects wore regular footwear and were free to use a cane. No physical assistance was given. The starting position was standardized so that the subjects commenced the test with their feet flat on the floor and their arms resting on the armrests. The testers used a stopwatch to time this activity. Each subject was asked to perform 3 test trials. The mean score was recorded.

\section{Depressive Symptoms}

Depressive symptoms were evaluated using the Turkish version of the Geriatric Depression Scale (GDS), which consists of 30 items. The total score of the scale is 0 to 30 points, where "O" indicates "no depression." "26,27

\section{Level of Independence}

Level of independence was evaluated by the Kahoku Aging Longitudinal Study Scale (KALS), which qualitatively evaluates the cognition and activities of the elderly in 12 areas. ${ }^{28}$ These areas are walking, going upstairs/downstairs, eating, washing, use of toilet, bathing, dressing, taking medicine, seeing, hearing, conversing, and using the telephone. Each activity was rated on a 4-point scale (0: dependent, 1-2: some help, 3: independent). A total score of 12 activities was recorded for the statistical analysis. In this scale, higher scores indicate higher level of independence.

\section{Quality of Life}

Quality of life (QoL) was measured by 0 - to $100-\mathrm{mm}$ visual analogue scales (VASs). Subjective ratings of health, appetite, sleep, daily mood, memory, familial relationships, relationships with friends and relatives, financial status, life satisfaction, and subjective rating of happiness were rated on 10 VASs. Higher points indicated higher level of QoL. For an overall QoL rating score, each scale was totaled and divided by $10 .^{28}$

\section{Statistical Analysis}

Statistical analysis was performed on a personal computer by using the Statistical Package for the Social Sciences 
version 12.0 (SPSS 12.0, demo, SPSS Inc., Chicago, IL). Demographic data were presented as n (\%). Quantitative and qualitative data were presented as mean (SD). The distribution of variables in study groups was assessed by Kolmogorov-Smirnov test, and where normal distribution was observed, data were compared by Student $t$ test for intergroup analyses; 95\% confidence intervals (95\% CI) were used for statistical significance.

\section{RESULTS}

Mean ages of the nursing home residents and subjects living at home were similar $(76.88$ [6.68] and 78.08 [6.61] years, respectively) (95\% CI: $-4.73,-2.33$ ). Sociodemographic characteristics (gender, age range, marital status) were also similar, as presented in Table 1.

Among home-dwelling elderly, only 3 (12\%) subjects were living alone and the remaining $22(88 \%)$ were living with their families.

Statistical analyses of the TUG test and KALS scores of the groups revealed that functional mobility and level of independence of the elderly people living at home were worse than those living in the nursing home $(95 \% \mathrm{CI}:-4.88$, -0.29 and $0.41,6.30$, respectively) (Table 2).

However, mean GDS score of the subjects living in the nursing home was higher than that of those living at home, indicating that nursing home residents were more depressed (95\% CI: 0.30, 5.45) (Table 2). Also QoL scores of the elderly living at home were higher than the nursing home residents (95\% CI: $-15.55,-2.93)$ (Table 2).

\section{DISCUSSION}

The main findings of this study indicated that functional mobility and independence level of the nursing home residents were higher than the home-dwelling elderly, but they had more depressive symptoms and their level of QoL was lower.

As a cultural characteristic, in Turkey, older people living at home usually share their lives with their family, and younger family members tend to take on many activities of the elderly. In the present study, most of the home-dwelling subjects $(88 \%)$ were living with their families, so receiving more help in daily activities than what is actually necessary may be the reason for the lower level of independency and functional mobility of the home-dwelling subjects when compared with the nursing home residents.

Research in the literature comparing functional mobility, level of independence, depressive symptoms, and QoL according to the residential status of the elderly is limited in number. ${ }^{28-32}$

Erdil et $\mathrm{al}^{1}$ found that some of the elderly living at home were dependent in activities such as paying bills, cleaning, washing clothes, and shopping.

Kerem et al ${ }^{29}$ compared physical, social, and psychological health of the elderly living at home and in a nursing home and stated that elderly living in the nursing home were more independent in self-care, walking, and stair-climbing activities.

Although not including a home-dwelling elderly group, the results of a cross-institutional study by Tada et $\mathrm{al}^{28}$ also reflect that independence in ADLs, which was assessed by KALS, was higher than expected in nursing home residents and also it was argued that nursing homes attach more importance to helping people remain as independent as possible in their daily lives. The results of the studies by Erdil et al, ${ }^{1}$ Kerem et $\mathrm{al}^{29}$ and Tada et $\mathrm{al}^{28}$ are parallel to the current study, which indicate that functional mobility and level of independence are higher in nursing home resident elderly individuals than their home-dwelling counterparts. In light of these findings, health care professionals and caregivers (including family members) may be recommended to be careful in placing restrictions on the daily activities of older people, and to take the underlying ability of the elderly into account, instead of simply providing care to the individual. This approach is thought to be parallel to the restorative care philosophy that focuses on helping elderly perform their ADLs as much as possible (washing their own face in comparison with having it done for them; walking to the dining room rather than being pushed in a wheelchair) and encouraging them to spend more time in physical activities rather than just sitting. ${ }^{33}$

Özer, ${ }^{30}$ in a study investigating the life satisfaction of elderly individuals living in family environment and nursing homes, stated that elderly living in a family environment had higher life satisfaction compared with those living in nursing homes.

Scocco et $\mathrm{al}^{34}$ investigated perceived QoL of the elderly who moved to a nursing home and found that QoL was

Table 1. Sociodemographic Characteristics of the Home-Dwelling and Nursing Home Resident Elderly People

\begin{tabular}{|c|c|c|c|c|}
\hline & $\begin{array}{l}\text { Nursing Home } \\
\text { Residents }(n=33) \\
n(\%)\end{array}$ & $\begin{array}{c}\text { Home-dwelling } \\
\text { Elderly }(n=25) \\
n(\%)\end{array}$ & $\chi^{2}$ & $P$ \\
\hline \multicolumn{5}{|l|}{ Gender } \\
\hline $\begin{array}{l}\text { Female } \\
\text { Male }\end{array}$ & $\begin{array}{l}10(30.3) \\
23(69.7)\end{array}$ & $\begin{array}{r}9(36) \\
16(64)\end{array}$ & 0.21 & .647 \\
\hline \multicolumn{5}{|l|}{ Age range } \\
\hline $\begin{array}{l}65-74 \\
74-84 \\
\geq 85\end{array}$ & $\begin{array}{c}13(39.4) \\
17(51.5) \\
3(9.1)\end{array}$ & $\begin{array}{r}8(32) \\
14(56) \\
3(12)\end{array}$ & 0.39 & .825 \\
\hline \multicolumn{5}{|l|}{ Current marriage status } \\
\hline $\begin{array}{l}\text { Single } \\
\text { Married } \\
\text { Widow/er, Divorced }\end{array}$ & $\begin{array}{l}7(21.2) \\
5(15.2) \\
21(63.6)\end{array}$ & $\begin{array}{r}6(24) \\
4(16) \\
15(60)\end{array}$ & 0.09 & .958 \\
\hline
\end{tabular}


Table 2. Comparison of the Timed Up $\mathbb{E}$ Go Test (seconds), Geriatric Depression Scale, Kahoku Aging Longitudinal Study Scale and Quality Of Life (mm) Scores Between The Groups

\begin{tabular}{|c|c|c|c|c|}
\hline & Nursing Home Residents $(n=33)$ & \multirow{2}{*}{$\frac{\text { Home-dwelling Elderly }(n=25)}{\text { Mean (SD) }}$} & \multicolumn{2}{|l|}{$95 \% \mathrm{Cl}$} \\
\hline & Mean (SD) & & Lower & Upper \\
\hline TUG & $12.32(4.16)$ & $14.91(4.52)$ & 4.88 & 0.29 \\
\hline GDS & $18.76(5.39)$ & $15.88(4.03)$ & 0.30 & 5.45 \\
\hline KALS & $25.81(5.79)$ & $22.45(5.21)$ & 0.41 & 6.30 \\
\hline QoL & $61.34(12.18)$ & $70.58(11.47)$ & 15.55 & 2.93 \\
\hline
\end{tabular}

TUG, Timed Up \& Go Test; GDS, Geriatric Depression Scale; KALS, Kahoku Aging Longitudinal Study Scale; QoL, Quality of Life.

perceived more poorly 6 months after moving to a nursing home. Feelings of loneliness and marginalization were among the reasons of decline in perceived QoL.

The duration of living in the nursing home was not recorded in our study. This is a limitation of this study but the lower level of QoL in nursing home residents may be discussed in parallel with the studies of Scocco et al, ${ }^{34}$ Özer, ${ }^{30}$ and Şahin and Yalçın, ${ }^{31}$ indicating that living with spouse/ relatives, strong relative relations, and living in a familiar environment were favorable circumstances for those living at home, and being estranged from the accustomed life style and feeling lonely and valueless were the unfavorable circumstances for the elderly living in nursing homes.

Prevalence and risk indicators of depression in elderly nursing home patients were investigated by Jongenelis et $\mathrm{al}^{35}$ and prevalence rates were found to be 3 to 4 times higher than in the community-dwelling elderly. In that study, loneliness and lack of social support, which were cited as factors related with lower level of QoL, were found to be risk indicators of depression also.

Chung ${ }^{32}$ compared extent of depression in the nursing home and community-dwelling Korean elderly people and found that community-dwelling older people had higher odds of depression. This finding was discussed as being a result of a significant increasing proportion of Korean elderly people living apart from their children.

In our study, most of the elderly living at home (88\%) were living with their relatives, and they had fewer depressive symptoms than their nursing home resident counterparts. This result was similar to the study of Kerem et $\mathrm{al}^{29}{ }^{29}$ in which home-dwelling elderly people were either living with a spouse or relatives, and were less depressed than the nursing home residents.

It is important to evaluate the elderly by a multidisciplinary team in respect to their capacity to continue their daily activities (physical performance, depressive symptoms, cognitive function, balance and other problems, QoL, and so forth) and to reflect potential problems.

For elderly people living at home, family members and other caregivers should be informed about the results of these evaluations. Also they should be advised that encouraging the elderly to take some responsibilities such as paying bills and taking grandchildren from school, encouraging them to perform hobbies, asking their opinions for any decision, and so forth, can be valuable in promoting autonomy and independence in older people. For the elderly living in nursing homes, giving psychological support and encouraging group activities and social interactions could be of benefit in supporting QoL and minimizing depressive symptoms. Leisure time activities may improve well-being by providing a sense of purpose (ie, self-efficacy), improving physiological efficiency through added exercise, and enhancing social integration by linking active individuals to friends and acquaintances in a structured context. ${ }^{36}$

In the literature, there are some studies supporting these recommendations, and showing that getting the elderly involved in leisure activities, family chores, hobbies, and so forth, would improve QoL and physical/psychological wellbeing.

Onishi et $\mathrm{al}^{37}$ investigated pleasurable recreational activities that older adults like to participate in, and the relationships between those activities and QoL. They stated that the amount of pleasure older adults experienced when engaging in activities such as conversation with family or neighbors showed significant association with the older adults' happiness, and also suggested that the presence of cohabitants and a hobby played an important role in QoL.

Hui et $\mathrm{al}^{38}$ studied the effects of dance on physical and psychological well-being of older persons, and pointed out that dancing, as a leisure time activity, had physical and psychological benefits.

Eyigor et $\mathrm{al}^{39}$ carried out a study to investigate the effects of group-based Turkish folkloric dances on physical performance, balance, depression, and QoL in 40 healthy adult elderly females older than 65 , and reported improvements in physical performance, balance, and QoL.

\section{CONCLUSION}

The present study represents the comparison results of functional mobility, depressive symptoms, level of independence, and quality of life of the Turkish elderly living at home and in the nursing home, and results may be thought to differ among different cultural structures such as American elderly people. Nevertheless, we think that these results reveal the need to investigate and compare the indicators of physical and psychological status of the elderly living in different residential facilities. Data that will be gained from these types of studies may be applicable to the related cultures, and will provide information for health care professionals to consider the areas that need support, while planning and carrying out institutional or home care for elderly people, and to contribute to the formation of home care models for older persons in order to give the services they need. 


\section{REFERENCES}

1. Erdil F, Senol Çelik S. Subaşı Baybuğa M. Aging in Turkey. Malta: International Institute on Ageing, United Nations (INIA); 2006.

2. Turkey Demographic and Health Survey, Ankara: Hacettepe University Institute of Population Studies Publications, 2003.

3. Shumway-Cook A, Ciol MA, Yorkston KM, et al. Mobility limitations in the Medicare population: Prevalence and sociodemographic and clinical correlates. J Am Geriatr Soc 2005;53:1217-1221.

4. Johnson CS, Mahon A, McLeod W. Nutritional, functional and psychosocial correlates of disability among older adults. J Nutr Health Aging 2006; 10:45-50.

5. Ozcan A, Donat H, Gelecek N, et al. The relationship between risk factors for falling and the quality of life in older adults. BMC Public Health 2005;5:90.

6. Kose N, Cuvalci S, Ekici G, et al. The risk factors for fall and their correlation with balance, depression, cognitive impairment and mobility skills in elderly nursing home residents. Saudi Med J 2005;26:978-981.

7. Bischoff HA, Stähelin HB, Monsch AU, et al. Identifying a cut-off point for normal mobility: A comparison of the timed 'up and go' test in community-dwelling and institutionalised elderly women. Age Aging 2003; 32:315-320.

8. Boulgarides LK, McGinty SM, Willet JA, et al. Use of clinical and impairment-based tests to predict falls by community-dwelling older adults. Phys Ther 2003;83:328-339.

9. Hatch J, Gill-Body KM, Portney LG. Determinants of balance confidence in community-dwelling elderly people. Phys Ther 2003;83: 1072-1079.

10. Steffen TM, Hacker TA, Mollinger L. Age and gender-related test performance in community-dwelling elderly people: Six-minute walk test, Berg balance scale, timed up \& go test and gait speeds. Phys Ther 2002;82:128-137.

11. Hellström Y, Persson G, Hallberg IR. Quality of life and symptoms among older people living at home. J Adv Nurs 2004;48:584-593.

12. Stalenhoef PA, Diederiks JPM, Knottnerus JA, et al. A risk model for the prediction of recurrent falls in community-dwelling elderly: a prospective cohort study. J Clin Epidemiol 2002;55:1088-1094.

13. Kauppila T, Pesinen A, Tarkkila P, et al. Cognitive dysfunction and depression may decrease activities in daily life more strongly than pain in community-dwelling elderly adults living with persistent pain. Pain Pract 2007;7:241-247.

14. Gardner DK, Helmes E. Interpersonal dependency in older adults and the risks of developing mood and mobility problems when receiving care at home. Aging Ment Health 2006;10:63-68.

15. Resnick B, Simpson M. Restorative care nursing activities: Pilot testing self-efficacy and outcome expectation measures. Geriatr Nurs 2003;24: 82-89.

16. Bonanni DR, Devers G, Dezzi K, et al. A dedicated approach to restorative nursing. J Gerontol Nurs 2009;35:37-44.

17. Galik EM, Resnick B, Gruber-Baldini A, et al. Pilot testing of the restorative care intervention for the cognitively impaired. J Am Med Dir Assoc 2008;9:516-522.

18. Resnick B, Simpson M, Bercovitz A, et al. Pilot testing of the restorative care intervention: impact on residents. J Gerontol Nurs 2006;32:39-47.

19. Vogt L, Wieland K, Bach M, et al. Cognitive status and ambulatory rehabilitation outcome in geriatric patients. J Rehabil Med 2008;40: 876-878.

20. Forster A, Lambley R, Hardy J, et al. Rehabilitation for older people in long-term care. Cochrane Database Syst Rev 2009;21:CD004294.
21. Inzitari M, Baldereschi M, Carlo AD, et al. Impaired attention predicts motor performance decline in older community-dwellers with normal baseline mobility: Results from the Italian Longitudinal Study on Aging (ILSA). J Gerontol A Biol Sci Med Sci 2007;62:837-843.

22. Harris JE, Eng JJ, Marigold DS, et al. Relationship of balance and mobility to fall incidence in people with chronic stroke. Phys Ther 2005;85: $150-158$.

23. Van Iersel MD, Kessels RPC, Bloem BR, et al. Executive functions are associated with gait and balance in community-living elderly people. J Gerontol A Biol Sci Med Sci 2008;63:1344-1349.

24. Güngen C, Ertan T, Eker E, et al. Reliability and validity of the standardized Mini Mental State Examination in the diagnosis of mild dementia in Turkish population. Turk Psikiyatri Derg 2002;13:273-281.

25. Podsiadlo D, Richardson S. The timed "Up \& Go": a test of basic functional mobility for frail elderly persons. J Am Geriatr Soc 1991;39: 142-148.

26. Sagduyu A. The Geriatric Depression Scale: A reliability and validity study in comparison with Hamilton Rating Scale for Depression. Turk Psikiyatri Derg 1997;8:3-8 [Turkish].

27. Ertan T, Eker E. Reliability, validity and factor structure of the geriatric depression scale in Turkish elderly: Are there different factor structures for different cultures? Int Psychogeriatr 2000;12:163-172.

28. Tada T, Yamamoto S, Morimoto T. Characteristics of the daily lives of elderly women at various facilities for the elderly. Nurs Health Sci 1999;1:13-18.

29. Kerem M, Meriç A, Kırd $l$ N, et al. Evaluation of elderly living at home and rest house. Turkish Journal of Geriatrics 2001;4:106-112.

30. Özer M. A study on the life satisfaction of elderly individuals living in family environment and nursing homes. Turkish Journal of Geriatrics 2004;7:33-36.

31. Şahin EM, Yalçın BM. Comparing the incidences of depression at the elderly living in nursing home or at their own homes. Turkish Journal of Geriatrics 2003;6:10-13.

32. Chung S. Residential status and depression among Korean elderly people: A comparison between residents of nursing home and those based in the community. Health Soc Care Community 2008;16:370-377.

33. Resnick B, Galik E, Pretzer-Aboff I, et al. Testing the reliability and validity of self-efficacy and outcome expectations of restorative care performed by nursing assistants. J Nurs Care Qual 2008;23:162-169.

34. Scocco P, Rapattoni M, Fantoni G. Nursing home institutionalization: A source of eustress or distress for the elderly? Int J Geriatr Psychiatry 2006; 21:281-287.

35. Jongenelis K, Pot AM, Eisses AMH, et al. Prevalence and risk factors of depression in elderly nursing home patients: The AGED study. J Affect Disord 2004;83:135-142.

36. Silverstein M, Parker MG. Leisure activities and quality of life among the oldest old in Sweden. Res Aging 2002;24:528-547.

37. Onishi J, Masuda Y, Suzuki Y, et al. The pleasurable recreational activities among community-dwelling older adults. Arch Gerontol Geriatr 2006;43:147-155.

38. Hui E, Chui BT, Woo J. Effects of dance on physical and psychological well-being in older persons. Arch Gerontol Geriatr 2009;49:e45-e50.

39. Eyigor S, Karapolat H, Durmaz B, et al. A randomized controlled trial of Turkish folklore dance on the physical performance, balance, depression and quality of life in older women. Arch Gerontol Geriatr 2009;48: 84-88. 